\title{
Chronic Dopamine D1, Dopamine D2 and Combined Dopamine D1 and D2 Antagonist Treatment in Cebus Apella Monkeys: Antiamphetamine Effects and Extrapyramidal Side Effects
}

\author{
L. Peacock, M.D., L. Hansen, M.D., F. Mørkeberg, M.D., and J. Gerlach, M.D., Ph.D.
}

To determine: (1) whether the apparent lack of efficacy of dopamine D1 (D1) antagonists in the clinic might be attributable to development of tolerance to antipsychotic effects; and (2) whether combined D1 and D2 antagonism might contribute to clozapine's clinical profile, eight Cebus apella monkeys were chronically treated with a D1 antagonist (NNC 756) ((+)-8-chloro-7-hydroxy-3-methyl5-(7-(2,3-dihydrobenzofuranyl)-2,3,4,5-tetrahydro-1H-3benzazepine), a D2 antagonist (raclopride) or a combination of the two antagonists. Prior neuroleptic exposure had resulted in oral dyskinesia in seven monkeys and sensitization to dystonia in all, yielding a model for acute and chronic extrapyramidal side effects (EPS).

Dextroamphetamine-induced motoric unrest and stereotypies were used as a psychosis model. We found tolerance toward dystonic symptoms during D1 and D1+ D2 treatments but not during D2 treatment. D2 but not
D1 or D1 + D2 antagonism caused exacerbation of dyskinesia. Both D1 and D1 + D2 antagonism were superior to D2 antagonism alone in counteracting the amphetamine-induced behaviors, with no tolerance to antiamphetamine effects. These findings suggest: (1) reasons other than tolerance (e.g., differences among antagonists) may explain the lack of efficacy in clinical trials with D1 antagonists; and (2) that D1 antagonism alone or combined and modest D1 and D2 antagonism offers the potential of antipsychotic efficacy with a lower risk of EPS than traditional D2 antagonism. Further clinical trials with D1 or combined D1 and D2 antagonists are, therefore, recommended.

[Neuropsychopharmacology 20:35-43, 1999] (C) 1998 American College of Neuropsychopharmacology. Published by Elsevier Science Inc.
KEY WORDS: Dopamine D1 antagonists; Dopamine D2 antagonists; Amphetamine; Extrapyramidal side effects; Dyskinesia; Dystonia; Monkeys

From the Research Institute for Biological Psychiatry, Sct. Hans Hospital, DK-4000 Roskilde, Denmark.

Address correspondence to: Dr. Linda Peacock, Research Institute for Biological Psychiatry, Sct. Hans Hospital, DK-4000 Roskilde, Denmark.

Received 24 October 1997; revised 21 April, 1998; accepted 30 April 1998.
In the search for new antipsychotics, animal studies have predicted the clinical development of dopamine D1-like (hereafter termed DA D1) antagonists to be a particularly promising avenue of research. Thus, DA D1 antagonists have robustly met criteria for antipsychotic potential in both rodents and nonhuman primates, and studies have also predicted a lesser potential for extrapyramidal side effects (EPS) in the form or dystonia and dyskinesia (Ellenbroek et al. 1989; Collins et al. 1991; Nielsen and Andersen 1992; Gerlach and 
Hansen 1993; Glenthøj et al. 1993; Waddington 1993; Lublin et al. 1994; Kakigi et al. 1995; Peacock and Gerlach, in press). Of especial interest is the rapid induction of tolerance to DA D1 antagonist-induced dystonia as opposed to the lack of/or minimal tolerance toward dystonia induced by traditional antipsychotics (i.e., DA D2 antagonists) (Coffin et al. 1989; Christensen 1990; McHugh and Coffin 1991; Gerlach and Hansen 1993; Lublin et al. 1993; Lublin et al. 1994; Casey 1995). Furthermore, it has been proposed that clozapine's unique clinical profile (high antipsychotic efficacy with low EPS potential) might either be attributable to its relatively strong blockade of DA D1 receptors, as compared to traditional antipsychotics $(40-50 \%$ vs. $0-30 \%$ ) or to its combined and modest blockade of both DA D1 and D2 receptors (maximum 50\% blockade of DA D2 receptors vs. $70-80 \%$ with traditional antipsychotics) (Coward et al. 1989; Farde et al. 1992; Gerlach and Hansen 1992; Gerlach 1991; Daly and Waddington 1994).

Opposed to the predictions from animal models, the clinical experience with DA D1 antagonists has been disappointing. Thus, although clinical trials with DA D1 antagonists have confirmed a low EPS potential, they have, at best, shown only a modest antipsychotic efficacy (de Beaurepaire et al. 1995; Den Boer et al. 1995; Karle et al. 1995; Karlsson et al. 1995). This incongruity between the results of animal models presumed predictive of antipsychotic potential and the clinical results to date leads to several questions. Among these are whether it might be that the tolerance to dystonia found to be so promising in relation to DA D1 antagonists' EPS potential, is also conferred to their antipsychotic efficacy (Barnes and Gerlach 1995). Another question is whether it might be fruitful to try to mimic clozapine's balanced and modest DA D1 and D2 antagonism. The intent of the present study is to address these two issues.

\section{METHODS}

\section{Animals}

Eight male Cebus apella monkeys were used. The monkeys had previously been treated with NNC 756 for 14 weeks and with raclopride for 14 weeks (Gerlach and Hansen 1993), and all were sensitized to acute EPS in the form of dystonia. Seven had developed mild-tomoderate oral dyskinesia (see Figure 1, placebo). The monkeys had been free of medication for 8 months prior to the present investigation.

During the investigation, the monkeys were housed in separate cages, under a 12-hour light/dark cycle, in a temperature- and humidity-regulated environment.

\section{Drugs and Design}

NNC 756 ((+)-8-chloro-7-hydroxy-3-methyl-5-(7-(2,3dihydrobenzofuranyl)-2,3,4,5-tetrahydro-1H-3-benzazepine) was used as a D1 antagonist, raclopride as a D2 antagonist, and saline as placebo. The doses of the antagonists were $2 / 3$ of the dose previously shown to produce dystonia when given alone and $1 / 3$ of the dystonic dose of each when combined (see below) (Gerlach and Hansen 1993). As a psychosis model, a fixed dose of dextroamphetamine $(0.25 \mathrm{mg} / \mathrm{kg})$, producing moderate arousal and motoric unrest and mild stereotypies (see Figure 2, and Figure 3) was used. The drugs were dissolved in saline immediately before their SC injection and were given as follows.

The antagonists were given daily for three periods of 10 days: first a combination of NNC $7560.006 \mathrm{mg} / \mathrm{kg}+$ raclopride $0.006 \mathrm{mg} / \mathrm{kg}$, then NNC $7560.012 \mathrm{mg} / \mathrm{kg}$ to four monkeys and raclopride $0.012 \mathrm{mg} / \mathrm{kg}$ to the other four (in randomized order) and, finally, the alternate antagonists to the four + four monkeys. A 4-day drugfree period was imposed between treatment phases.

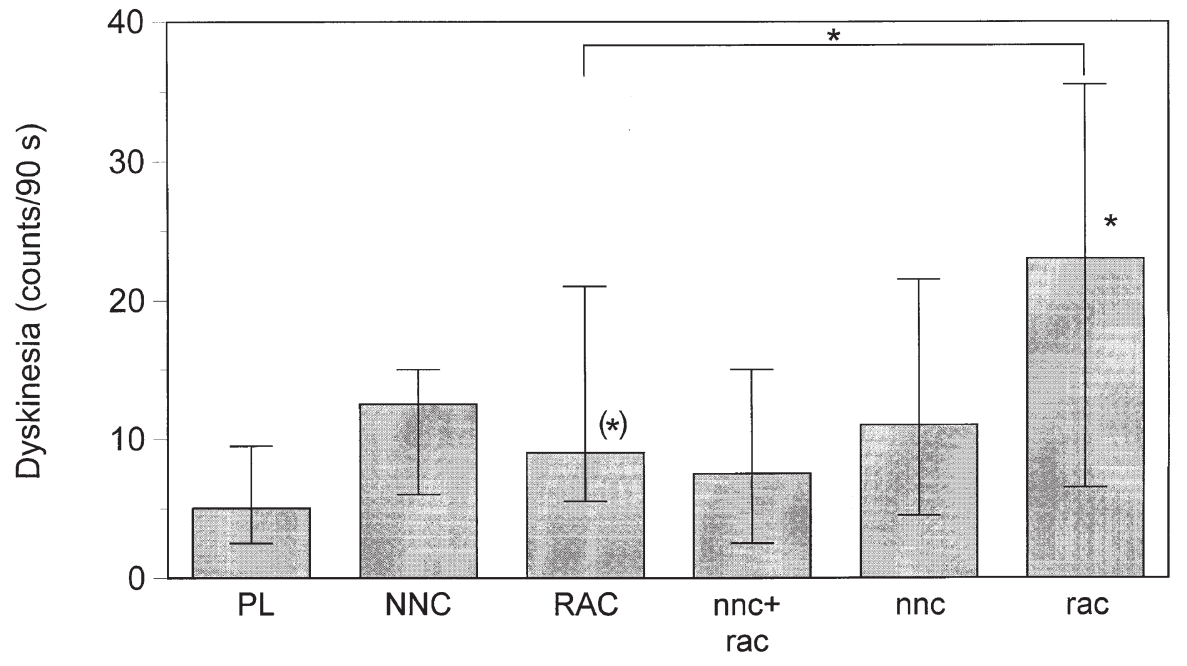

Figure 1. Dyskinesia (counts/90 s). 


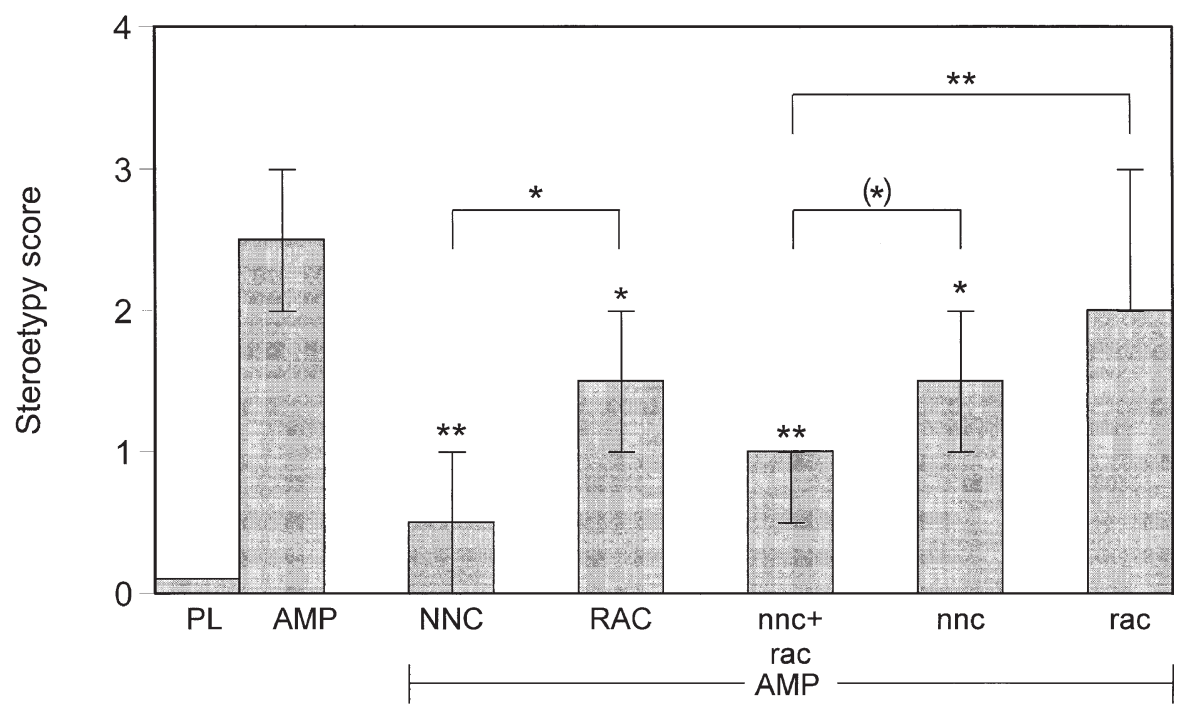

Figure 2. Stereotypy score.

Before the study and at the end, the monkeys were tested with saline (no significant difference in any behavioral parameters). Before the study, in the middle and the end, the monkeys were tested with dextroamphetamine given alone (no significant difference in amphetamine effects). During each antagonist treatment period, dextroamphetamine was also given in combination with the antagonists (simultaneously by separate injection) on days 3 and 10 to test for tolerance toward antiamphetamine effects.

After the study, acute tests were performed with raclopride $0.006 \mathrm{mg} / \mathrm{kg}$ and NNC $7560.006 \mathrm{mg} / \mathrm{kg}$ alone and combined with dextroamphetamine 0.025 $\mathrm{mg} / \mathrm{kg}$ to allow comparison with the effects of the combination of the two antagonists. Tests with dextroamphetamine $0.025 \mathrm{mg} / \mathrm{kg}$ alone and saline showed no significant differences in any behavioral parameters, as compared to the tests in the chronic study. All sessions were videotaped and later rated by an investigator blind to the given medication.

\section{Evaluation}

The monkeys' behaviors were rated at time 0 and at 15min intervals for a period of $90 \mathrm{~min}$. Oral dyskinesia was rated by actual counts/time period. Sedation, bradykinesia, dystonia, arousal, motoric unrest, and stereotypy were rated on a scale from 0 to 6 (Table 1). All parameters were rated at baseline for each session, and for each drug and drug combination.

\section{Statistics}

The data were evaluated by means of Friedman's test followed by Wilcoxon's paired test for nonparametric data, when Friedman's test was significant. The accepted level

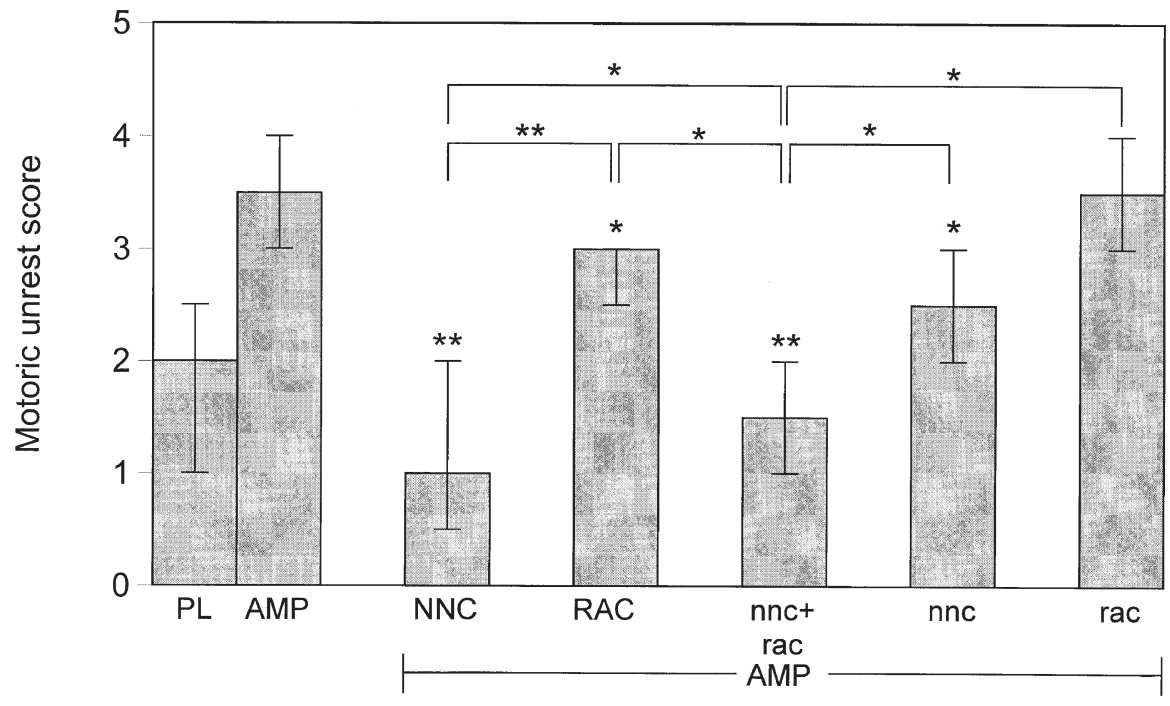

Figure 3. Motoric unrest score. 
Table 1. Evaluation

\begin{tabular}{llc}
\hline Behavior Rating Scale & Score \\
\hline Sedation & $\begin{array}{c}\text { Degree of drowsiness/sleep ranging } \\
\text { from awake to sleeping and cannot } \\
\text { be awakened even by gross stimuli, } \\
\text { e.g. hand clapping } \\
\text { Degree of slow/stiffened movements } \\
\text { ranging from normal tempo and } \\
\text { flexibility to fixed, maintained postures } \\
\text { Degree of sustained abnormal posture or } \\
\text { stiffened movements (catalepsy)/clonic } \\
\text { movements of the head, neck, limbs, and } \\
\text { trunk, gaping and grimacing (dystonia) } \\
\text { Degree of awakeness/vigilance ranging } \\
\text { from not awake to extreme vigilance in } \\
\text { relation to self or the environment } \\
\text { Motoric activity including fidgeting in } \\
\text { place or movement in space }\end{array}$ & $0-6$ \\
Motoric unrest & Persistent repetition of senseless movements & $0-6$ \\
Stereotypy & & \\
\hline
\end{tabular}

The effects of the drugs were evaluated by means of the following rating scales 0 , not present; 1 , extremely mild (can be a variation of the normal); 2 , mild (slightly more pronounced than normal); 3 , mild to moderate; 4 , moderate to severe (behavior pronounced but discontinuous); 5 , severe; 6 , extremely severe (behavior continuous).

of significance was $p<.05$; whereas, $p<.1$ was accepted as a tendency. The effect of the drugs is indicated by bar graphs expressing the median of the scores for the eight animals over the first $90 \mathrm{~min}$ after drug injection. Because the results cannot be expected to follow a Gaussian distribution, the interquartile range is used as a measure of the spread. The interquartile range is the length of the interval containing the central $50 \%$ of observations.

\section{RESULTS}

There were neither significant changes in antagonist effects rated on days 1 and 7, nor significant changes in antiamphetamine effects rated on days 3 and 10 (see Table 1 and Table 2). Therefore, to facilitate the written and graphic presentation of data, the means of the ratings for days 1 and 7 and days 3 and 10, respectively, are used in the following. However, data from the different trial days are provided in Table 2 and Table 3.

\section{EFFECTS OF NNC 756 AND RACLOPRIDE}

\section{Sedation}

Each of the antagonist treatments (NNC 756, $0.012 \mathrm{mg} /$ $\mathrm{kg}$; raclopride, $0.012 \mathrm{mg} / \mathrm{kg}$; and NNC 756 + raclopride, $0.006 \mathrm{mg} / \mathrm{kg}$ of each), produced significant sedation as

Table 2. Antagonist Effects

\begin{tabular}{|c|c|c|c|c|c|c|c|c|}
\hline & \multicolumn{2}{|c|}{ Placebo } & \multicolumn{2}{|c|}{ NNC $0.012 \mathrm{mg} / \mathrm{kg}$} & \multicolumn{2}{|c|}{$\mathrm{RAC} 0.012 \mathrm{mg} / \mathrm{kg}$} & \multicolumn{2}{|c|}{$\begin{array}{c}\text { NNC } 0.006+ \\
\text { RAC } 0.006 \mathrm{mg} / \mathrm{kg}\end{array}$} \\
\hline & Before & After & Day 1 & Day 7 & Day 1 & Day 7 & Day 1 & Day 7 \\
\hline \multicolumn{9}{|l|}{ Sedation } \\
\hline Median & 0.5 & 0.5 & 2 & 2 & 2 & 2 & 2 & 2 \\
\hline Range & $0-1$ & $0-1$ & $1-3$ & $1-4$ & $1-2$ & $0-3$ & $1.5-3$ & $1.5-3$ \\
\hline \multicolumn{9}{|c|}{ Bradykinesia } \\
\hline Median & 0 & 0 & 1.5 & 1 & 1.5 & 0.5 & 1.5 & 1 \\
\hline Range & $0-0$ & $0-0$ & $1-3$ & $1-2$ & $0-2$ & $0-2$ & $0-3$ & $0-2$ \\
\hline \multicolumn{9}{|l|}{ Dystonia } \\
\hline Median & 0 & 0 & 0.5 & 0 & 0 & 0 & 0 & 0 \\
\hline Range & $0-0$ & $0-0$ & $0-1$ & $0-0$ & $0-0$ & $0-1$ & $0-1$ & $0-1$ \\
\hline \multicolumn{9}{|l|}{ Dyskinesia } \\
\hline Median & 5 & 4 & 13.5 & 10 & 12 & 6 & 5.5 & 9 \\
\hline Range & $0.5-7$ & $2-13$ & $6.5-17$ & $5-12$ & $5-22$ & $5-16$ & $2.5-11$ & $2-20$ \\
\hline
\end{tabular}

Sedation, bradykinesia, dystonia, and dyskinesia days 1 and 7 of D1, D2, and combined D1 and D2 antagonist treatment and during placebo before and after the antagonist trials. In all cases comparisons between days 1 and 7 and between placebo before and after were nonsignificant. 
Table 3. Antiamphetamine effects.

\begin{tabular}{|c|c|c|c|c|c|c|c|c|c|}
\hline & \multicolumn{3}{|c|}{$\begin{array}{c}\text { Amphetamine } \\
\mathrm{mg} / \mathrm{kg}\end{array}$} & \multicolumn{2}{|c|}{$\begin{array}{c}\text { NNC } 0.012 \\
\mathrm{mg} / \mathrm{kg}\end{array}$} & \multicolumn{2}{|c|}{$\begin{array}{c}\text { RAC } 0.012 \\
\mathrm{mg} / \mathrm{kg}\end{array}$} & \multicolumn{2}{|c|}{$\begin{array}{c}\text { NNC } 0.006+ \\
\text { RAC } 0.006 \\
\text { mg/kg }\end{array}$} \\
\hline & Before & During & After & Day 3 & Day 10 & Day 3 & Day 10 & Day 3 & Day 10 \\
\hline \multicolumn{10}{|l|}{ Arousal } \\
\hline Median & $4-5$ & 5 & 4.5 & 1.5 & 1.5 & 3 & 3 & 2 & 1.5 \\
\hline Range & $3-5$ & $4-5$ & $3.5-5$ & $1-2.5$ & $1-2$ & $2-4$ & $2-3.5$ & $1.5-2$ & $1-2$ \\
\hline \multicolumn{10}{|l|}{ Stereotypy } \\
\hline Median & 2 & 3 & 3 & 0 & 0 & 1.5 & 1 & 1 & 0 \\
\hline Range & $1.5-3.5$ & $2-3$ & $1-3$ & $0-1$ & $0-1$ & $1-2$ & $1-2$ & $1-1$ & $0-1$ \\
\hline \multicolumn{10}{|c|}{ Motoric unrest } \\
\hline Median & 4 & 4 & 3 & 1.5 & 1 & 3 & 3 & 1 & 1 \\
\hline Range & $2.5-4.5$ & $3-4$ & $2.5-4$ & $0-2$ & $0-2$ & $1.5-3$ & $2-3$ & $1.5-2.5$ & $0.5-2$ \\
\hline
\end{tabular}

compared to placebo, with no significant differences between the treatments (Figure 4). As seen from Table 2, there was no tolerance to sedation with any of the antagonist treatments.

NNC 756, $0.006 \mathrm{mg} / \mathrm{kg}$ given alone also produced significant sedation; whereas, raclopride, $0.006 \mathrm{mg} / \mathrm{kg}$ did not (Figure 4). There was no significant difference in the degree of sedation produced by NNC $756+$ raclopride and NNC 756, $0.006 \mathrm{mg} / \mathrm{kg}$ given alone.

\section{Bradykinesia and Dystonia}

Both NNC 756, $0.012 \mathrm{mg} / \mathrm{kg}$ alone and NNC $756+$ raclopride resulted in significant bradykinesia, as compared to placebo; whereas, raclopride, $0.012 \mathrm{mg} / \mathrm{kg}$ alone only tended to produce bradykinesia (Figure 5). Comparing the treatments to one another, there was no significant difference in the induction of bradykinesia.
Although it might seem from Table 2 that tolerance to bradykinesia occurred in all antagonist treatment groups, there were no significant differences between days 1 and 7 in any group attributable to a number of animals having unchanged scores.

NNC 756, $0.012 \mathrm{mg} / \mathrm{kg}$ alone resulted in catalepsy (dystonia degree $=1$ ) in six monkeys on day 1 , this effect disappearing in three monkeys, lessening in two (being of shorter duration), and remaining unchanged in one, on day 7. NNC 756 + raclopride caused catalepsy in three monkeys on day 1 , this effect diminishing in two, and remaining unchanged in one, on day 7. Raclopride, $0.012 \mathrm{mg} / \mathrm{kg}$ resulted in catelepsy in three animals on day 1 , this effect lessening in two, and worsening in one, on day 7. Furthermore, one monkey, which did not have any dystonic reaction on day 1 of raclopride, developed moderate dystonia (degree 3) on day 7 of raclopride treatment. Neither NNC 756 nor

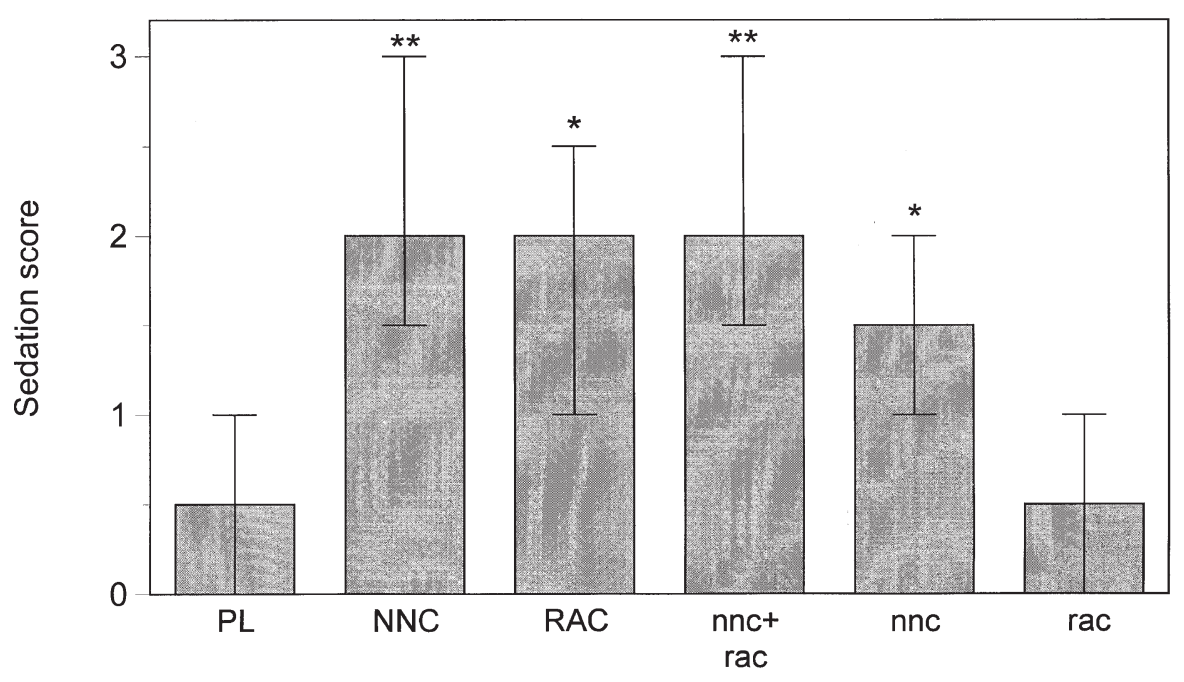

Figure 4. Sedation score. 


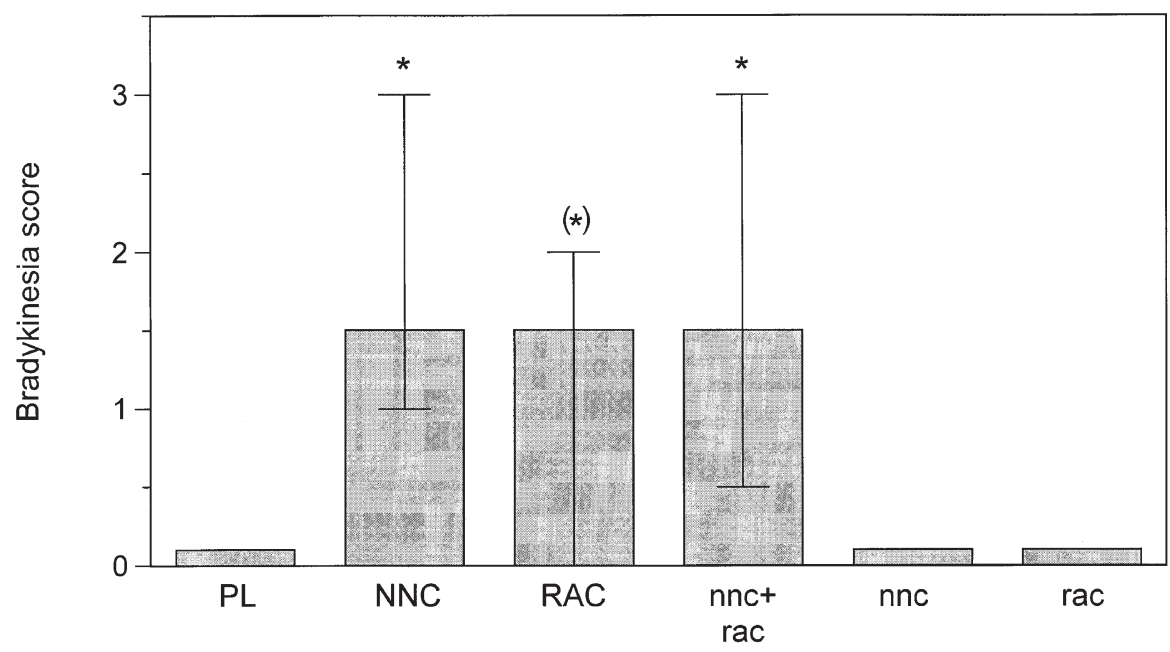

Figure 5. Bradykinesia score.

raclopride, $0.006 \mathrm{mg} / \mathrm{kg}$ given alone caused bradykinesia or dystonic reactions in any of the animals.

\section{Dyskinesia}

As previously stated, seven of the monkeys had mildto-moderate oral dyskinesia (Figure 1). Neither NNC 756, $0.012 \mathrm{mg} / \mathrm{kg}$ alone nor NNC 756 + raclopride resulted in any difference as compared to placebo; whereas, raclopride, $0.012 \mathrm{mg} / \mathrm{kg}$ alone tended to result in increased dyskinesia (Figure 1). Considering Table 2, it might seem that dyskinesia increased during the D1 antagonist and combined D1 and D2 antagonist treatments, falling during the D2 antagonist treatment. There were no significant differences between days 1 and 7 however, because some animals remained unchanged, some increased, and some decreased scores in all treatment groups.
Raclopride, $0.006 \mathrm{mg} / \mathrm{kg}$ significantly increased oral dyskinesia both as compared to placebo (Figure 1) and to raclopride, $0.012 \mathrm{mg} / \mathrm{kg}(p<.05)$, but not as compared to NNC 756 + raclopride. NNC 756, $0.006 \mathrm{mg} / \mathrm{kg}$ produced no difference as compared to placebo, NNC 756, $0.012 \mathrm{mg} / \mathrm{kg}$, or NNC 756 + raclopride.

\section{ANTIAMPHETAMINE EFFECTS OF NNC 756 AND RACLOPRIDE}

Dextroamphetamine, $0.25 \mathrm{mg} / \mathrm{kg}$ induced a syndrome of moderate-to-extreme arousal, mild-to-moderate stereotypical behavior and moderate motoric unrest (Figure 2, Figure 3, and Figure 6). Each animal had its own characteristic reaction. While some monkeys moved about the cage, in a repetitive pattern, others remained in place, shifting from side to side with rapid scanning

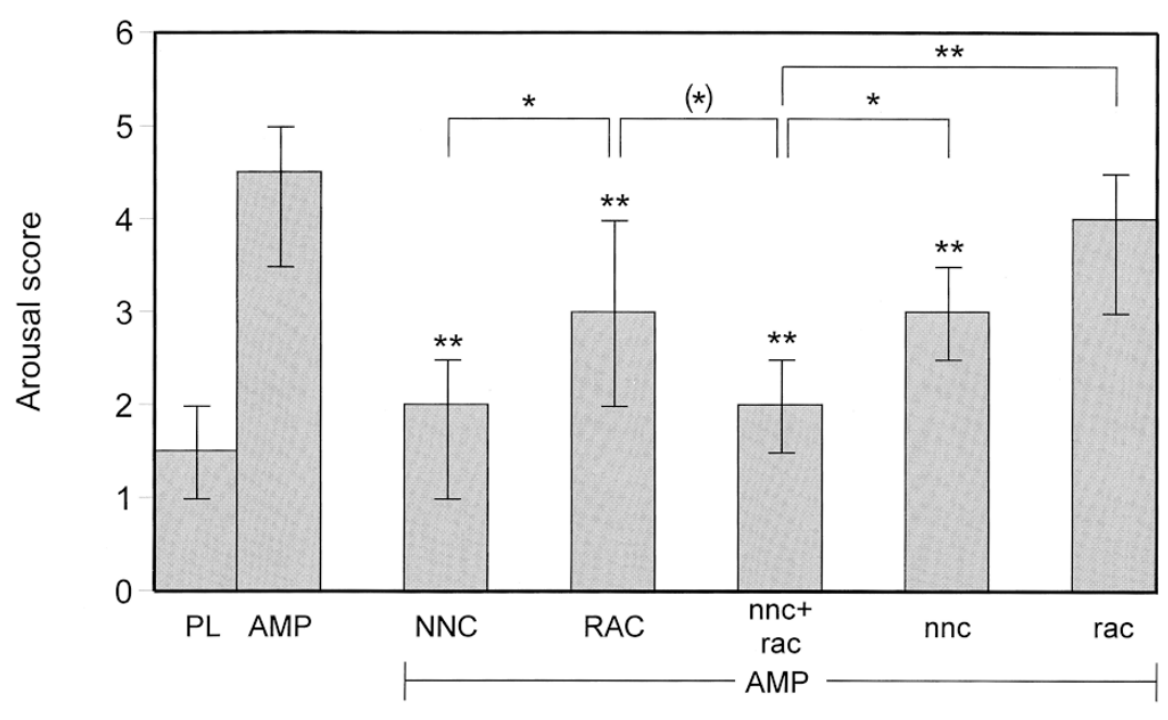

Figure 6. Arousal score. 
movements of the head. Some of the animals appeared hallucinated; for example, gazing fixed by a spot where nothing of objective interest could be seen.

\section{Arousal}

NNC 756, $0.012 \mathrm{mg} / \mathrm{kg}$, raclopride, $0.012 \mathrm{mg} / \mathrm{kg}$ and NNC 756 + raclopride, $0.006 \mathrm{mg} / \mathrm{kg}$ of each, all significantly reduced amphetamine induced arousal, NNC 756 being significantly superior to raclopride but not to NNC 756 + raclopride (Figure 6). NNC 756 + raclopride tended to be superior to raclopride in the lessening of arousal. As seen from Table 3, no tolerance occurred to any of the antagonists' effects upon amphetamine induced arousal.

NNC 756, $0.006 \mathrm{mg} / \mathrm{kg}$ also significantly reduced amphetamine-induced arousal; whereas, raclopride, $0.006 \mathrm{mg} / \mathrm{kg}$ did not (Figure 6). NNC 756 + raclopride caused a significantly greater reduction of arousal than NNC 756, $0.006 \mathrm{mg} / \mathrm{kg}$ and raclopride, $0.006 \mathrm{mg} / \mathrm{kg}$ alone.

\section{Stereotypy}

NNC 756, $0.012 \mathrm{mg} / \mathrm{kg}$, NNC 756 + raclopride, 0.006 $\mathrm{mg} / \mathrm{kg}$ of each and raclopride, $0.012 \mathrm{mg} / \mathrm{kg}$ all significantly reduced amphetamine-induced stereotypy (Figure 2). NNC 756 was superior to raclopride but not to raclopride + NNC 756. No tolerance occurred to any of the antagonists' antistereotypical effects, indeed, the scores fell from days 1 to 7 or remained unchanged (Table 3).

$\mathrm{NNC} 756,0.006 \mathrm{mg} / \mathrm{kg}$ also significantly reduced amphetamine-induced stereotypy; whereas, raclopride, 0.006 $\mathrm{mg} / \mathrm{kg}$ had no significant effect (Figure 2). The combination of raclopride + NNC 756 only tended to be superior to NNC 756, $0.006 \mathrm{mg} / \mathrm{kg}$ alone in counteracting amphetamine-induced stereotypy; whereas, it was significantly superior to raclopride $0.006 \mathrm{mg} / \mathrm{kg}$ alone.

\section{Motoric Unrest}

NNC 756, NNC 756 + raclopride and raclopride all significantly inhibited amphetamine induced motoric unrest (Figure 3). NNC 756 was superior to raclopride and to NNC 756 + raclopride; whereas, NNC 756 + raclopride was superior to raclopride. No tolerance occurred to any of the antagonists' effects upon motoric unrest, scores either falling or remaining unchanged, although two monkeys in the raclopride group did have a higher score on day 7 than 1 (Table 3 ).

NNC 756, $0.006 \mathrm{mg} / \mathrm{kg}$, but not raclopride, $0.006 \mathrm{mg} /$ $\mathrm{kg}$, significantly reduced amphetamine-induced motoric unrest (Figure 3). The combination of NNC $756+$ raclopride was superior both to NNC 756, $0.006 \mathrm{mg} / \mathrm{kg}$ and to raclopride $0.006 \mathrm{mg} / \mathrm{kg}$ alone in combating amphetamine induced motoric unrest.

\section{DISCUSSION}

As stated in the introduction, the present investigation was conducted to illuminate two aspects of the potential role of D1 antagonism in the quest for new antipsychotics. These two were: (1) to clarify whether the tolerance to dystonia seen during chronic D1 antagonism is conferred to the antipsychotic potential as predicted by antiamphetamine effects; and (2) to determine whether combination of modest D1 and D2 antagonism might offer advantages over D1 or D2 antagonism alone.

\section{Effects of Chronic D1 Antagonism}

In this study, no tolerance developed toward the antiamphetamine effects of the D1 antagonist NNC 756. That a 10-day treatment period was sufficient to observe tolerance is supported both in other studies (Christensen 1990; Gerlach and Hansen 1993; Lublin et al. 1993; Lublin et al. 1994; Casey 1995) and in the present investigation. Thus, catalepsy disappeared or lessened in five of the six animals having this reaction.

Based on our results, insofar as the amphetamine model is reliable in predicting antipsychotic efficacy, tolerance to the antipsychotic effects of D1 antagonists may not explain the lack of efficacy found in the clinical trials. As for the model's reliability, studies of a number of potential and proved antipsychotics have shown an extremely good match between our results and those found in the clinic (e.g., that neither SDZ 912 nor -(3) PPP would be viable alternatives to traditional neuroleptics; whereas, seroquel shows promise) (Peacock and Gerlach 1993; Peacock and Gerlach, in press). The only apparent exceptions are results of clinical trials with D1 antagonists, but the D1 antagonists that reached the clinic were not those tested in the model (because they were not made available to us).

Experience with D1 antagonists in the clinic is, indeed, very limited. Thus far, only four trials have been conducted, three with SCH 39166 and one with NNC 687. Although the trial with NNC 687 showed modest results, the trials with $\mathrm{SCH} 39166$ were especially confounding, because they not only indicated a lack of the expected antipsychotic efficacy, but, to the contrary, pointed to a possible exacerbation of psychosis.

As an alternative explanation of the outcome of the clinical trials, we are currently pursuing the proposal raised by others that all D1 antagonists are not equal. Thus, there is a growing body of evidence that some D1 antagonists as traditionally defined by antagonism of dopamine-induced stimulation of cAMP, may have agonist effects either at another, undiscovered D1 receptor or at an unexplored D1 receptor transducer system (e.g. inositol phosphatase) (Mailman et al. 1986; Rogers et al. 1990; Wachtel and White 1991; Daly and Waddington 1993; Downes and Waddington 1993; Latinen 1993; Gi- 
ambalvo and Wagner 1994; Undie et al. 1994; Deveney and Waddington 1995).

\section{Effects of D1 + D2 Antagonism and Either D1 or D2 Antagonism}

All of the chronic antagonist treatments resulted in slight, but significant, sedation and bradykinesia, with no significant difference between the treatments and with no development of tolerance toward these effects. Although an element of sedation can be a desirable effect in the treatment of agitated psychotic states, the induction of bradykinesia implies that any of these treatment modalities entails a risk of EPS in the form of parkinsonism.

Considering the potential to induce other EPS, whereas there was a trend toward improvement of dystonic symptoms during treatment with the D1 antagonist and the combined D1 + D2 antagonist treatment, results with the D2 antagonist were mixed. Thus, although dystonic symptoms lessened in two animals treated with raclopride, they worsened in two, one animal having no signs of dystonia on day 1 and having moderate dystonia on day 7 . These findings support an advantage of D1 antagonism and indicate a possible advantage of D1 + D2 antagonist antagonism over D2 antagonism in relation to an on-going dystonic potential.

As to dyskinesia, neither NNC 756 alone nor the combination of NNC 756 + raclopride aggravated oral dyskinesia, whereas, raclopride did. These findings again point to an advantage of either D1 antagonism alone or combined D1 + D2 antagonism, as compared to D2 antagonism in relation to EPS. That raclopride, $0.006 \mathrm{mg} / \mathrm{kg}$ resulted in significantly greater dyskinesia than raclopride, $0.012 \mathrm{mg} / \mathrm{kg}$ might be explained by the bradykinetic effects of the latter dose, because it has been well established that parkinsonian side effects can mask dyskinesia (Nordic Dyskinesia Study Group 1986). That NNC 756, $0.006 \mathrm{mg} / \mathrm{kg}+$ raclopride 0.006 $\mathrm{mg} / \mathrm{kg}$ did not exacerbate oral dyskinesia, whereas, raclopride, $0.006 \mathrm{mg} / \mathrm{kg}$ did, when given alone, might again be explained by the bradykinetic effects of the combination treatment, although an alternative explanation also seems viable. Thus, the element of D1 antagonism in the combined treatment may have counterbalanced the dyskinetic effects of the D2 antagonism (for discussion, see Peacock and Gerlach 1997). This would explain why the combined treatment, although not more bradykinetic than raclopride, $0.012 \mathrm{mg} / \mathrm{kg}$, did not aggravate dyskinesia; whereas, raclopride at this dose did.

Summing up the results as to counteraction of the amphetamine-induced syndrome, both NNC 756, 0.012 $\mathrm{mg} / \mathrm{kg}$ and NNC 756 + raclopride were superior to raclopride $0.012 \mathrm{mg} / \mathrm{kg}$ in decreasing arousal, stereotypies, and motoric unrest. Furthermore, although NNC 756, $0.006 \mathrm{mg} / \mathrm{kg}$ alone was significantly effective in reducing all amphetamine-induced behaviors, its combination with an ineffective dose of raclopride caused even greater suppression. These findings indicate that combined elements of D1 and D2 antagonism can supplement one another as to antipsychotic efficacy.

\section{CONCLUSIONS}

The present study supports a role for D1 antagonism in antipsychotic therapy. Thus, according to our findings, either D1 antagonism alone or combined and modest D1 and D2 antagonism, offers the potential of providing antipsychotic efficacy with a lesser risk of dystonia and dyskinesia than traditional D2 antagonism. Based upon the present findings and the considerations mentioned in the discussion, we recommend further clinical trials with other D1 antagonists, both given alone and in combination with D2 antagonists.

\section{REFERENCES}

Barnes TRE, Gerlach J (1995): D1 receptor antagonists in schizophrenia. Psychopharmacology 121:287-288

Casey DE (1995): The effects of D1 (NNC 22-0215) and D2 (haloperidol) antagonists in a chronic double-blind placebo controlled trial in cebus monkeys. Psychopharmacology 121:289-293

Christensen AV (1990): Long-term effects of dopamine D1 and D2 antagonists in vervet monkeys. Behavioral Neurol 3:49-60

Coffin VL, Latranyi MB, Chipkin RE (1989): Acute extrapyramidal syndromes in Cebus monkeys: Development mediated by dopamine D2 but not D1 receptors. J Pharmacol Exp Ther 249:769-774

Collins P, Broekkamp CLE, Jenner P, Marsden CD (1991): Drugs acting at D-1 and D-2 dopamine receptors induce identical purposeless chewing in rats which can be differentiated by cholinergic manipulation. Psychopharmacology 103:503-512

Coward DM, Imperato A, Urwyler S, White TG (1989): Biochemical and behavioral properties of clozapine. Psychopharmacology 99:S6-S12

Daly SA, Waddington JL (1993): Behavioral evidence for "D-1-like" dopamine receptor subtypes in rat brain using the new isochroman agonist A 69930 and isoquinoline antagonist BW737C. Psychopharmacology 113:45-50

Daly SA, Waddington JL (1994): The effects of clozapine on behavioral responses to the selective "D1-like" dopamine receptor agonist, A 68930, and to the selective "D2like" agonist, RU 24213. Br J Pharmacol 133:839-844

de Beaurepaire R, Labelle A, Naber D, Jones BD, Barnes TRE (1995): An open trial of the D1 antagonist SCH 39166 in six cases of acute psychotic states. Psychopharmacology 121:323-2721

Den Boer JA, van Megan HJGM, Fleischhacker WW, Louwerens JW, Slaap BR, Westenberg HGM, Burrows GD, 
Srivastava ON (1995): Differential effects of the D1-DA receptor antagonist SCH 39166 on positive and negative symptoms of schizophrenia. Psychopharmacology 121: 317-322

Deveney AM, Waddington JL (1995): Pharmacological characterization of behavioural responses to SK\&F 83959 in relation to "D1-like" dopamine receptors not linked to adenylyl cyclase. Br J Pharmacol 116:2120-2126

Downes RP, Waddington JL (1993): Grooming and vacuous chewing induced by SK\&F 83959, an agonist of dopamine "D1-like" receptors that inhibits dopamine-sensitive adenylyl cyclase. Eur J Pharmacol 234:135-136

Ellenbroek B, Willemen A, Cools A (1989): Are antagonists of dopamine D1 receptors drugs that attenuate both positive and negative symptoms of schizophrenia? A pilot study in Java monkeys. Neuropsychopharmacology 2:191-199

Farde L, Nordstrom A-L, Wiesel F-A, Pauli S, Halldin C, Sedvall G (1992): Positron emission tomographic analysis of central D1 and D2 dopamine receptor occupancy in patients treated with classical neuroleptics and clozapine. Relation to extrapyramidal side effects. Arch Gen Psychiatr 49:538-544

Gerlach J (1991): New antipsychotics: Classification, efficacy, and adverse effects. Schizophr Bull 17:289-309

Gerlach J, Hansen L (1992): Clozapine and D1/D2 antagonism in extrapyramidal functions. Br J Psychiatr 160:34-37

Gerlach J, Hansen L (1993): Effect of chronic treatment with NNC 756, a new D-1 receptor antagonist, or raclopride, a D-2 receptor antagonist, in drug-naive Cebus monkeys: Dystonia, Dyskinesia, and D1-D2 supersensitivity. J Psychopharm 7:355-364

Giambalvo CT, Wagner RL (1994): Activation of D1 and D2 dopamine receptors inhibits protein kinase $\mathrm{C}$ activity in striatal synaptosomes. J Neurochem 63:168-176

Glenthøj B, Bolwig TG, Hemmingsen R (1993): Effects of chronic discontinuous and chronic continuous treatment of rats with a dopamine D1 receptor antagonist (NNC-756). Eur J Pharmacol 242:281-291

Kakigi T, Gao X-M, Tamminga CA (1995): Drug-induced oral dyskinesias in rats after traditional and new neuroleptics. J Neural Transm (Gen Sect) 101:41-49

Karle J, Clemmesen L, Hansen L, Andersen M, Andersen J, Fensbo C, Sloth-Nielsen M, Skrumsager B, Lublin H, Gerlach J (1995): NNC 01-687, a selective dopamine D1 receptor antagonist, in the treatment of schizophrenia. Psychopharmacology 121:328-329

Karlsson P, Smith L, Farde L, Harnryd C, Sedvall G, Wiesel F-A (1995): Lack of apparent antipsychotic effect of the D1 dopamine receptor antagonist SCH 39166 in acutely ill schizophrenic patients. Psychopharmacology 121:309-316

Latinen JT (1993): Dopamine stimulates K+ efflux in the chick retina via D1 receptors independently of adenelyl cyclase activation. J Neurochem 61:1461-1469
Lublin H, Gerlach J, Peacock L (1993): Chronic treatment with the D1 receptor antagonist, SCH 23390, and the D2 receptor antagonist, raclopride, in cebus monkeys withdrawn from previous haloperidol treatment: Extrapyramidal syndromes and dopaminergic supersensitivity. Psychopharmacology 112:389-397

Lublin H, Gerlach J, Mørkeberg F (1994): Long-term treatment with low doses of the D1 antagonist NNC 756 and the D2 antagonist raclopride in monkeys previously exposed to dopamine antagonists. Psychopharmacology 114:495-504

Mailman RB, Schulz DW, Kilts CD, Lewis MH, Rollema H, Wyrick S (1986): Biochemical and functional studies of D-1 dopamine receptors. Psychopharmacol Bull 22:593598

McHugh D, Coffin V (1991): The reversal of extrapyramidal side effects with SCH 39166, a dopamine D1 receptor antagonist. Eur J Pharmacology 202:133-134

Nielsen E, Andersen P (1992): Dopamine receptor occupancy in vivo: Behavioral correlates using NNC-112, NNC687, and NNC-756, new selective D-1 Receptor antagonists. Eur J Pharmacol 219:35-41

Nordic Dyskinesia Study Group (1986): Effect of different neuroleptics in tardive dyskinesia and parkinsonism: A video-controlled multicenter study with chlorprothixine, perphenazine, haloperidol, and haloperidol + biperiden. Psychopharmacology 90:423-429

Peacock L, Gerlach J (1993): Effects of several partial dopamine D2 receptor agonists in Cebus apella monkeys previously treated with haloperidol. Eur J Pharmacol 237:329-340

Peacock L, Gerlach J (1997): A reanalysis of the dopamine theory of tardive dyskinesia: The hypothesis of dopamine D1/D2 imbalance. In Yassa R, Nair NPV, Jeste DV (eds), Neuroleptic-Induced Movement Disorders. Cambridge, Cambridge University Press, pp 141-160

Peacock L, Gerlach J (in press) New and old antipsychotics versus clozapine in a monkey model: Adverse effects and antiamphetamine effects. Psychopharmacology

Rogers DC, Hunter AJ, Hill RG (1990): Relationship between behavioral activation and adenylate cyclase activity induced by the dopamine D1 receptor agonists 80723 , 83565, and 83959. Soc Neurosci Abstr 16:1054

Undie AS, Weinstock J, Sarau HM, Friedman E (1994): Evidence for a distinct D1-like receptor that couples to activation of phosphoinositide metabolism in brain. J Neurochem 62:2045-2048

Wachtel SR, White FJ (1991): The D1 dopamine receptor antagonist SCH 23390 exerts agonist-like effects on rat nucleous accumbens neurons. Soc Neurosci Abstr 17:1353

Waddington JL (1993): Pre- and postsynaptic D1 and D5 receptor mechanisms in relation to antipsychotic activity. In Barnes $\mathrm{T}$ (ed), Antipsychotic Drugs and Their Side Effects. San Diego, Academic Press, pp 66-85 